\title{
SUSTAINABILITY OF DIGITAL PUBLIC SPACES
}

\author{
DOI: 10.12776/QIP.V19I1.381
}

\section{MATEJ HUDÁK}

Received 2 September 2014, Revised 15 September 2014, Accepted 15 November 2014

\begin{abstract}
Purpose: Modern digital public spaces are evolving from being mostly the provider of ICT and internet connection to institutions that provide complex range of services and support for the community. With this shift in their focus new challenges are emerging, among others their sustainability.
\end{abstract}

Methodology/Approach: We build on and extend the methodology of Digital Cooperatives project. Within this project, survey on 59 digital public spaces from 12 EU countries was conducted. These digital public spaces were examined in 21 areas, some of them relating to their sustainability. We further analyse the sustainability issue of these digital public spaces.

Findings: We identified three main issues affecting sustainability of digital public spaces - budgeting, services and community. Digital public spaces mostly rely on public funding and have limited diversification of their funds, which increases a risk when one source of funding drops out. They also have to build a strong community of users, supporters, which will make use of their capacities and helps co-create new services and thus strengthen and improve the community itself.

Originality/Value of paper: Research in this paper is based on the collection of best practices from various EU countries in the field of digital public spaces. Recommendations based on these practices could help the creation of new, and in current digital public spaces.

Keywords: digital public space; sustainability; budgeting, innovative digital public space 


\section{INTRODUCTION}

Nowadays, digital public spaces, or telecentres, are facing new challenges. With the evolution of ICT and shifts in people's and community's needs, modern digital public spaces are evolving. They used to be mostly the provider of ICT and internet connection, but now they have to transform into institutions that provide complex range of services and support for the community.

Digital public spaces or telecentres "present a huge opportunity for extending ICT access to rural communities in a flexible manner" (Mayanja, 2007). These digital public spaces are "established in many countries as a means of providing access to information and communication technologies (ICTs) in order to enhance community development" (Bailey and Ojelanki, 2009, p.1). "Telecentres are a physical space that provides public access to information and communication technologies, notably the Internet, for educational, personal, social, and economic development" (Reilly and Gómez, 2001, p.1).

Modern innovative digital public spaces have to overcome traditional definitions (e.g. Reilly and Gómez, 2001, p.1; Masiero, 2011, p.1 or Oestmann and Dymond, 2001, p.3), thus have to be more than physical centres providing ICT's and connectivity for all kinds of personal/community development. "Telecentres are being established in communities with the objective of improving social and economic development and the empowerment of citizens" (Bailey, 2009, p.1). They have to be primarily implementers of community's needs.

Nowadays, as stated by Campbell (2001, p.124) "consensus reigns on the fact that investment in human capital has become a more significant source of wealth creation than investment in land or physical capital. If the digital divide is represented by uneven access to ICT inputs and outputs, then a widening digital divide could lead directly to a widening economic divide between industrialized and developing countries." The issue of digital public spaces, or telecentres, is closely related to digital divide defined by Tiene (2002, p.211) or Campbell (2001, p.124); or described trough skills and usage of ICT by Van Dijk and Hacker (2003, pp.323-324). Also Abdulwahab and Dahalin (2010, p.268) stated that "the conception of Telecentre is a proven essential tool for addressing the digital divide by providing the unserved and or underserved populations access to ICT resources that could not have been afforded privately". According to Oestmann and Dymond (2001, p.1) "Telecentres have considerable potential for narrowing the digital divide in remote, rural and otherwise disadvantaged communities."

With this shift in focus of digital public spaces, or telecentres, new challenges are emerging, among others their sustainability. Telecentres are expected to be sustainable in the long term as their socio-economic impact and the opportunity cost of alternative modes of delivery are realised. Thus, almost all telecentres involve public/government support, but with an eye to eventual selfsustainability. Most also charge for their services, but not always at full cost. (Oestmann and Dymond, 2001, p.8) Moreover, "telecentres must continually adapt to their specific local contexts if they are to be sustainable" (Bailey, 2009, 
p.12). Purpose of this paper is to address the issues affecting sustainability of current digital public spaces in their evolution to modern innovative ones.

\section{METHODOLOGY}

Methodology of this paper is based on INTERREG IVC project Digital Cooperatives (acronym E-COOP). Within this project, partners from 12 European Union countries conducted a study on digital public spaces in 21 areas during 2013-2014 period. These areas covered all features and characteristics of digital public spaces from their innovation, planning, citizenship involvement to their sustainability in order to provide relevant stakeholders and policy makers policies in developing and implementing of "E-COOPS", new innovative model of digital public spaces based on digital mediation, deeper involvement of citizens and other stakeholders, co-building new and innovative e-services with users and actively encouraging creative projects through a more dynamic and cooperative environment.

The study was conducted on 59 digital public spaces from 12 EU countries, from which 41 were fully described and evaluated. For our analyses we reduced our sample to 36 digital public spaces because some of the practices provided insufficient information. Moreover, for the purpose of our analysis, we divided these digital public spaces to:

- Physical and Web-based;

- Traditional and Other.

Distribution of the sample can be seen in Table 1 and 2. We have to note, that under the term of Traditional digital public spaces we understand physical places that provide not only ICT and internet connection, but also variety of courses, information and services for their users or for the community.

Table 1 - Sample distribution on Physical and Web-based digital public spaces

\begin{tabular}{l|c|c|c}
\hline Country & Physical & Web-based & Summary \\
\hline Finland & & 1 & 1 \\
\hline France & 3 & 2 & 5 \\
\hline Greece & 3 & 1 & 4 \\
\hline Hungary & 3 & 1 & 4 \\
\hline Italy & 3 & & 3 \\
\hline Poland & 3 & 2 & 5 \\
\hline Romania & & 1 & 1 \\
\hline Slovak Republic & 1 & 4 & 4 \\
\hline Spain & 3 & 1 & 1 \\
\hline Sweden & & 1 & 3 \\
\hline UK & 2 & 1 & $\mathbf{3 6}$ \\
\hline Summary & $\mathbf{2 1}$ & $\mathbf{1 5}$ & \\
\hline
\end{tabular}


Table 2 - Sample distribution on Traditional and Other digital public spaces

\begin{tabular}{l|c|c|c}
\hline Country & Other & Traditional & Summary \\
\hline Finland & 1 & & 1 \\
\hline France & 5 & & 5 \\
\hline Greece & 2 & 2 & 4 \\
\hline Hungary & 3 & 1 & 3 \\
\hline Italy & 1 & 2 & 5 \\
\hline Poland & 4 & 1 & 1 \\
\hline Romania & 1 & & 5 \\
\hline Slovak Republic & 5 & & 4 \\
\hline Spain & 1 & 3 & 3 \\
\hline Sweden & 1 & & $\mathbf{3 6}$ \\
\hline UK & 1 & 2 & $\mathbf{1 1}$ \\
\hline Summary & $\mathbf{2 5}$ & & \\
\hline
\end{tabular}

\section{RESULTS}

Budget of the digital public space is one of the key elements of its sustainability. We examined percentage of public funding on total budget of digital public spaces and number of funding sources. Under public funding we understand all kind of public resources that digital public spaces receive through various types of projects from European Union, government and local authorities; and other projects funded by other organizations (e.g. NGOs), local sponsors etc. We also have to note, that membership fees and gifts are considered as one source of funding regardless of the number of members and donors. Moreover, if digital public spaces had more than 20 different sources of funding, we assigned them number 20 as their number of sources.

We can see that budget of almost all Physical digital public spaces consists only from public funding (Figure 1) and is diversified from 1 to 3 sources (Figure 2). On the other hand, dependency on public funding among Web-based ones is less distinct, though their number of funds is also relatively low. 


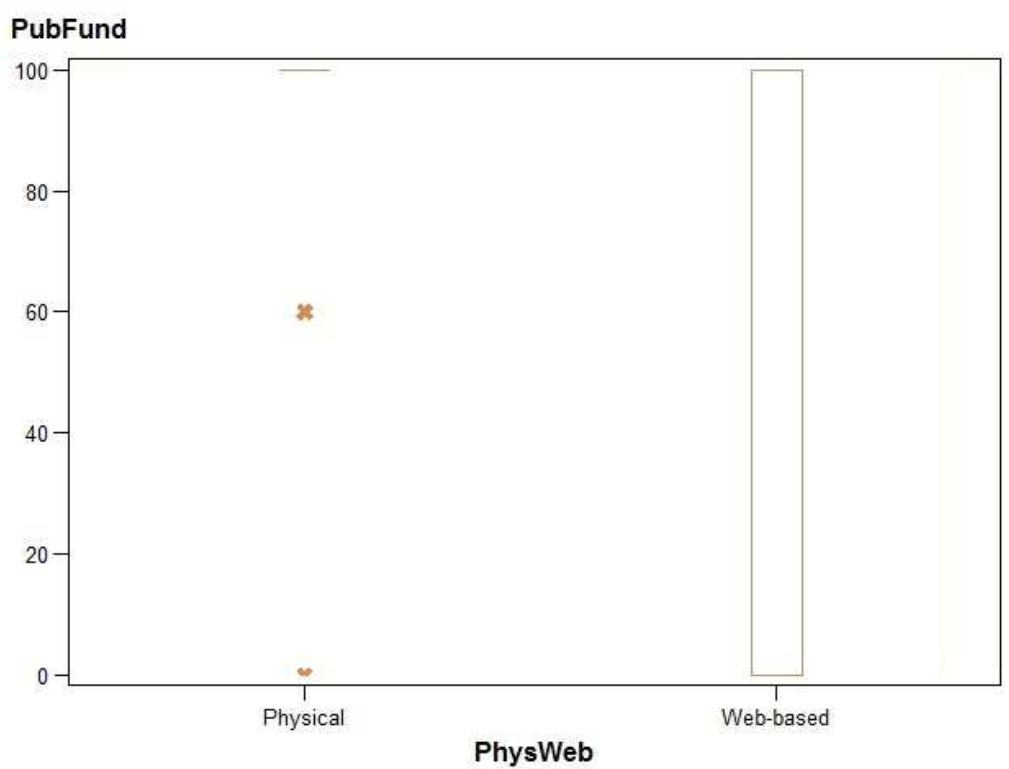

Figure 1 - Box-plot of percentage of public funding in Physical and Web-based DPSes

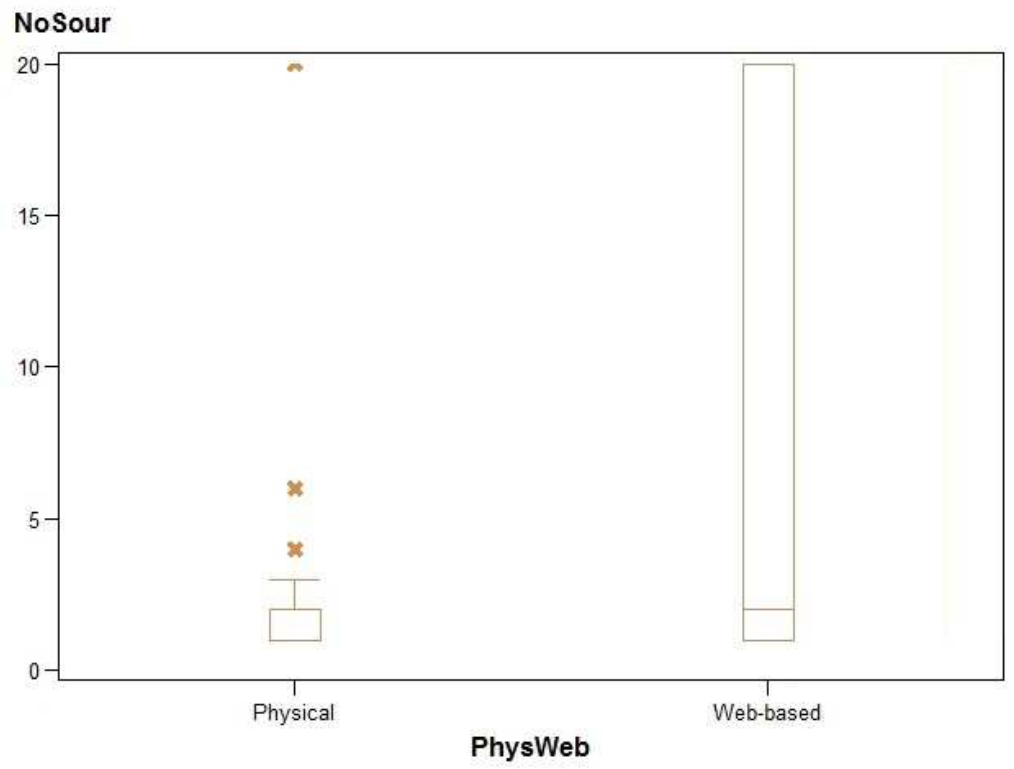

Figure 2 - Box-plot of number of funding sources in Physical and Web-based DPSes

When we take into account the division on Traditional digital public spaces and Other, we can see that 9 of 11 Traditional ones depend solely on public funding (Figure 3). Other digital public spaces also depend mainly on public funding. Number of budget sources is similar in both groups (Figure 4). 
When we consider the whole sample, 25 digital public spaces are dependent solely on public funding (Table 3). Only 2 of them diversify their sources extensively, i.e. in their case they run more than 20 projects. On the other hand, only 3 digital public spaces do not use public funding and largely diversify their sources.

Table 3 - Contingency table of percentage of public funding and number of funding sources

\begin{tabular}{c|c|c|c|c|c|c|c|c}
\hline & \multicolumn{7}{|c|}{ Number of funding sources } & \\
\hline Percentage of public funding & $\mathbf{1}$ & $\mathbf{2}$ & $\mathbf{3}$ & $\mathbf{4}$ & $\mathbf{5}$ & $\mathbf{6}$ & $\mathbf{2 0}$ & Summary \\
\hline 0 & 1 & 3 & & & & & 3 & $\mathbf{7}$ \\
\hline 60 & & 1 & & & & & & $\mathbf{1}$ \\
\hline 75 & & 1 & & & & & & $\mathbf{1}$ \\
\hline 88 & & & & & 1 & & & $\mathbf{1}$ \\
\hline 90 & & 1 & & & & & & $\mathbf{1}$ \\
\hline Summary & 16 & 3 & 1 & 2 & & 1 & 2 & $\mathbf{2 5}$ \\
\hline
\end{tabular}

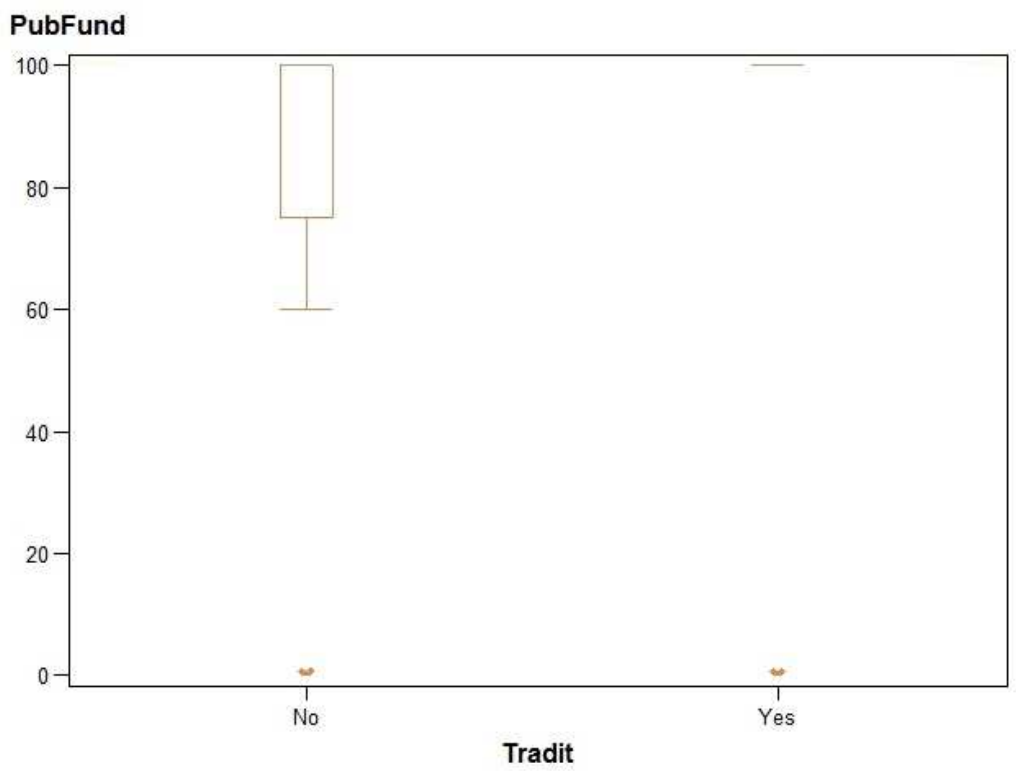

Figure 3 - Box-plot of percentage of public funding in Traditional and other DPSes 


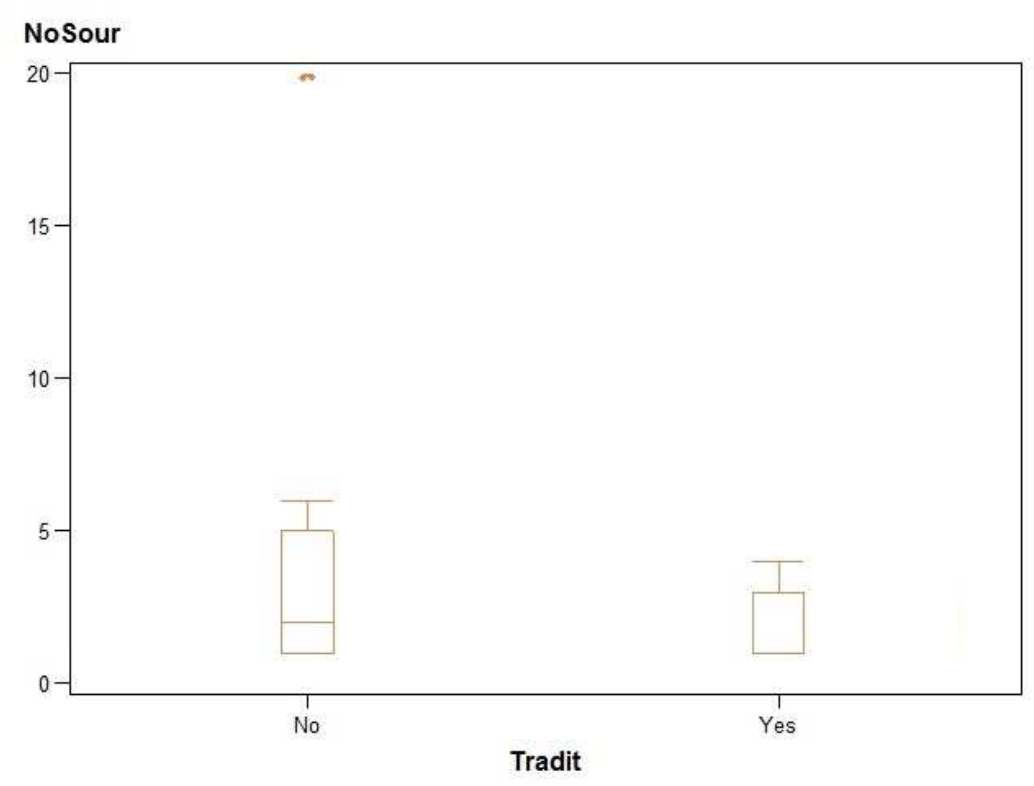

Figure 4-Box-plot of number of funding sources in Traditional and other DPSes

\section{CONCLUSION}

In this paper we analysed 36 practises identified within the INTERREG IVC Digital Cooperatives project from the perspective of their sustainability. In order to survive, new innovative model of digital public spaces have to be developed. These new digital public spaces have to be based on digital mediation, deeper involvement of community and co-building innovative and creative e-services.

We identified three main issues affecting sustainability of current digital public spaces - budgeting, services and community. Majority of digital public spaces rely mostly on public funding and have limited diversification of their funds. 25 of analysed practises are dependent solely on public funding, 16 of them actually have only one source of funding.

Future innovative digital public spaces also have to build a strong community around them, which will help co-create new innovative services and thus strengthen and improve the community itself. From our point of view, these spaces will have to be combination of Physical and Web-based centres and will have to be Traditional (as defined for the purposes of this paper). As seen on published figures and tables, Web-based digital public spaces have lower dependency on public funding and use more sources of funding. On the other hand, in our opinion, these spaces do not create such cohesive and dedicated community as Traditional and Physical centres.

Next generation innovative digital public spaces will have to reduce dependency on public funding and diversify sources of their funding, or at least strongly 
diversify their public funds (e.g. running several EU or domestic projects as seen in some cases). Some innovative approaches seen in our sample included crowdfunding, volunteering, combining digital public space with incubator, or mixed business - non-profit approach.

Paper contributes to the existing body of knowledge by research based on the collection of best practices from various EU countries in the field of digital public spaces. Recommendations presented in this paper could help the creation of new, and in current digital public spaces.

\section{ACKNOWLEDGEMENT}

This paper was prepared as part of INTERREG IVC's project 1038R4 Digital Cooperatives (E-COOP).

\section{REFERENCES}

Abdulwahab, L. and Dahalin, Z. M., 2010. A Conceptual Model of Unified Theory of Acceptance and Use of Technology (UTAUT) Modification with Management Effectiveness and Program Effectiveness in Context of Telecentre. African Scientist, 11(4), pp.267-275.

Bailey, A. and Ojelanki, N., 2009. Social ties, literacy, location and the perception of economic opportunity: Factors influencing telecentre success in a development context. System Sciences, HICSS'09. 42nd Hawaii International Conference on IEEE, pp.1-11.

Bailey, A., 2009. Issues affecting the social sustainability of telecentres in developing contexts: A field study of sixteen telecentres in Jamaica. The Electronic Journal of Information Systems in Developing Countries, 36(4), pp.118.

Campbell, D., 2001. Can the digital divide be contained?. International labour review, 140(2), pp.119-141.

Masiero, S., 2011. Financial Vs Social Sustainability of Telecentres: Mutual Exclusion or Mutual Reinforcement? The Electronic Journal on Information Systems in Developing Countries, 45(3), pp.1-23.

Mayanja, M., 2007. Rethinking telecentre sustainability approaches. The Journal of Community Informatics, 2(3), n.p.

Oestmann, S. and Dymond, A. C., 2001. Telecentres-Experiences, lessons and trends. In Latchem, C. and Walker, D. ed., 2001. Perspectives on Distance Education. Telecentres: Case Studies and Key Issues. Vancouver: The Commonwealth of Learning, Ch.1., pp. 1-15.

Reilly, K. and Gómez R., 2001. Comparing approaches: telecentre evaluation experiences in Asia and Latin America. The Electronic Journal of Information Systems in Developing Countries, 4(3), pp.1-17. 
Tiene, D., 2002. Addressing the global digital divide and its impact on educational opportunity. Educational Media International, 39(3-4), pp.212-222.

Van Dijk, J. and Hacker, K., 2003. The digital divide as a complex and dynamic phenomenon. The information society, 19(4), pp.315-326.

\section{ABOUT THE AUTHOR}

Matej Hudák, Ing., PhD. - University of Economics in Bratislava, Faculty of Business Economics with seat in Košice, Department of Quantitative Methods; Tajovského 13, 04130 Košice, Slovak Republic; e-mail: matej.hudak@euke.sk 